\title{
Water related disasters in urban areas: a case study of a city in north-east India
}

\author{
N. Sharma \\ DHI India, Guwahati, India
}

\begin{abstract}
As we know, any disaster whether it is natural or manmade, creates serious disruption in the normal life of urban citizens causing widespread loss of properties and human lives along with the destruction of the environment. Out of all types of disasters, the water related disasters i.e. floods, are most common in the north eastern part of India, due to the occurrence of heavy rainfall resulting from extremely dynamic monsoon regimes, the unique physiographic settings, cyclones and the presence of numerous streams, rivers and water bodies. Since the population patterns in urban areas are fast changing and due to the increase in developmental activities, open spaces are fast diminishing, the misery of the people caused by artificial flood related disasters have increased manifold. Flooding in urban areas is mainly the result of poor drainage and inefficient management of land and water. Shortage of water storage areas and difficulties in transporting all the precipitation as surface water normally leads to flooding in most of the urban towns and cities.

Therefore, a proper response system is necessary to mitigate the impact of the flood disaster through preparedness, to create awareness among the people about hazard occurrence and its management through relief and rehabilitation and to draw up some short and long term plans to deal with affected people in vulnerable areas.

This paper will present a case study on how effectively the response systems are capable of mitigating the misery of the affected citizens of one of the premier cities of north east India in particular and what more is required to be done to make the city free from artificial flood hazards.

Keywords: disaster, environment, rainfall, cyclones, streams, water bodies, misery, mitigate, hazard, relief and rehabilitation, manifold.
\end{abstract}




\section{Introduction}

Impact of flood wherever it occurs is one of the most significant water related disasters of this region resulting in loss of lives and disrupts economic activities. So far flood disaster management has been more or less limited to reactive response only. But the time has come to change this reactive response to proactive response to increase the effectiveness of management and reduce the loss of life and properties. A comprehensive and suitable plan with holistic approach by the concerned authorities is required to be formulated to attain sustainable development. In past few years urban flooding has become a serious problem to the city of Guwahati, known as the gateway to the north-east region of India. Attention of disaster management authority in India towards urban floods have started growing only after the Mumbai floods in 2005. The National Disaster Management Authority (NDMA) of India has then decided to address the Urban flooding as a separate disaster which also led to the formulation of flood guidelines and its release in 2008.Urban flooding has now become a universal phenomenon and poses a great challenge to urban planners all over the world.

\section{Causes of flooding [1]}

\subsection{Natural causes}

Out of various natural causes the following three causes are considered important: (i) heavy rainfall, (ii) topography of the land, and (iii) lack of proper drainage.

\subsection{Manmade causes [2]}

Important man made causes are as follows: (i) population increase, (ii) deforestation, (iii) encroachment on drainage channel, (iv) urbanization, (v) lack of attention to hydrological system, and (vi) lack of co-ordination between the multiple authorities in the city.

\section{Effect of flooding and flood damage}

Every section of people living in urban areas is affected when flood occurs, some of the effects are as below.

\subsection{Economic effects}

Economic losses are due to damage of residential buildings work places, loss of employment to daily earners, loss of transport and communication system, price rise of essential commodities, etc. 


\subsection{Environmental effect}

Damage to the surrounding forests, human and animal, parks, water bodies, shrubs and fruit/vegetable trees results imbalance of the eco-system of the city and sometimes creating health hazards to the citizens.

\subsection{Health effect}

Flooding usually brings infectious diseases like fever, dysentery, common cold, dengue, dermatological diseases, etc. and not only to human beings but animals and birds are also badly affected.

\subsection{Effect on traffic}

Damage to roads, culverts and bridges causing disruption in movement of traffic affects day to day life of the citizens. Diversion of traffic in the cities from flooding streets to non-flooding streets creates congestion and causes great inconvenience to the commuters and public.

\section{A case study: flooding in Guwahati City in north east India [3]}

\subsection{Topography}

The geographical location of Guwahati City is $90^{\circ} 33^{\prime} 18^{\prime \prime} \mathrm{E}$ and $91^{\circ} 10^{\prime} 41^{\prime \prime} \mathrm{E}$ longitudes and $25^{\circ} 50^{\prime} 33^{\prime \prime} \mathrm{N}$ and $26^{\circ} 15^{\prime} 50^{\prime \prime} \mathrm{N}$ latitudes. Guwahati City is a regional hub and gateway to north-east India (Figure 1) [4]. Guwahati also has a bitter effect on urban growth such as defective roads, drainage system and storage of open space, etc. The main city where the flooding is predominant is located on the southern bank of the Brahmaputra River which has its extension on the northern bank also. It is situated on an undulating plain with altitudes varying from $49.5 \mathrm{~m}$ to $55.5 \mathrm{~m}$ above mean sea level. The southern and eastern side is completely and the northern side partially surrounded by hill locks. The central part of the city has small hillocks. The city is also covered by swamps and water bodies (Figure 2).

\subsubsection{Population}

According to the 2011 census, Guwahati City had a population of 968,549 which witnessed a very high rate of growth in the period from 1971 to 1991 i.e. around $8.1 \%$ per annum may be due large number of migrants from neighbouring country Bangladesh. After 1991 the rate has declined to almost $2.5 \%$ per annum. Considering this rate the estimated present population of the city has crossed the 12 lakh figure. With this trend the projected population in Guwahati will cross 25 lakh figure by 2030 . 


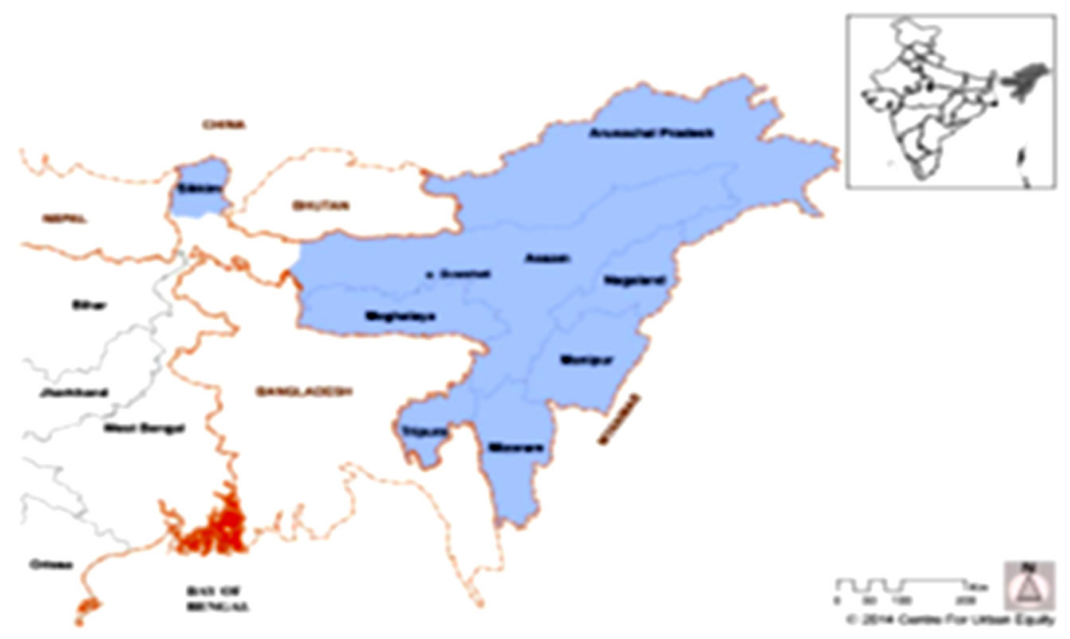

Figure 1: Location map of Guwahait in north east India.

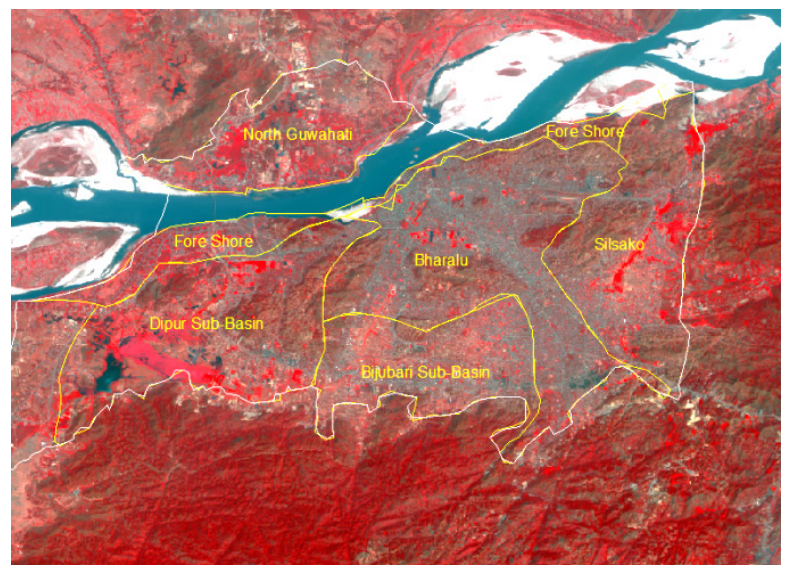

Figure 2: Map showing delineation of watersheds within Guwahati.

\subsubsection{Climate [5]}

Guwahati has a humid subtropical climate (Köppen climate classification $C w a$ ), falling just short of a tropical savanna climate (Köppen climate classification $A w$ ). The average annual temperature is $24.2^{\circ} \mathrm{C}$ with extremes ranging from $40.6^{\circ} \mathrm{C}$ recorded on April 24, 2014 to $3.0^{\circ} \mathrm{C}$ recorded in January, 1964. Maximum monthly precipitation and maximum number of days with precipitation [6] in a month in Guwahati during the last two decades i.e. 1991 to 2010 are $375 \mathrm{~mm}$ and 20 days respectively. 


\subsection{Causes of flooding}

The problem of the city during the rainy season is very severe, (rainy days as high as 20 in a month) when a major areas of the city is under water after a heavy rain of an hour or two. The problem is aggravated with inflows of surface runoffs from the surrounding hills and swelling Brahmaputra River. Out of various causes the following are considered as prime causes of flood in this city: (a) insufficient natural drainage, (b) silting of the drains, (c) inadequate capacity of the artificial drainage, (d) unauthorized construction in the wetland areas, and (e) decrease of surface area available for infiltration into the soil due to construction of building, impervious parking areas, etc. thereby redirecting the rainwater into the drains is another cause of flooding in the city.

\subsubsection{Drainage basins of the city}

Greater Guwahati has six drainage basins [4] with only two main drainage channels, namely Bharalu and Basistha-Bahini Rivers which ultimately drain into the Brahmaputra River directly or indirectly. The names of the drainage basins are as below and their area of delineation is shown in the map in Figure 2:

(a) Bharalu Basin. The area of the basin is approximately 4,200 hectares and carries the flow through the Bharalu River into the Brahmaputra River directly. The basin is the most flood prone having several pockets of low lying areas and back flow nature from Brahmaputra during rainy season.

(b) Deepor Beel. This is the largest drainage basin having 20,135 hectares located on the southern part of the city comprising $2 / 3$ hilly areas and $1 / 3$ plain areas. Run-off from this basin is carried through Basistha-Bahini River which discharges into Deepor Beel connected to the Brahmaputra River at the western outskirt of Guwahati.

(c) Silsako Basin. This basin covers an area of 6,534 hectares and located on the south eastern part of Guwahati. The water from the area drains into Silsako Beel first and run into the Brahmaputra through Bondajan channel.

(d) Solabeel. Which consists of Borsola Beel and Sorusola Beel, is located on the south-western part of the city covering an area of 11 hectares and 4 hectares respectively.

(e) Foreshore Basin. This is a very small area that include some residential, commercial and institutional area. Water accumulates due to rain drains out to the Brahmaputra River through number of small drains as the area is at a high altitude.

(f) North Guwahati Basin. This basin covers an area of 3,230 hectares and is located on the northern bank of the Brahmaputra River. As the area is at a higher level, water from the basin drains into the Brahmaputra River directly or through small streams like Ghorajan. The current natural drainage of Guwahati metropolitan area on the south bank of the Brahmaputra is mainly through the Bharalu River and Baistha Bahini River flowing into the Deepor Beel. The Deepor Beel also receives discharge from a large part of the city and adjoining hills on southern side and ultimately disposes the discharges in to the Brahmaputra through Khona River. 


\subsubsection{Major flood affected areas of the city [7]}

The following roads and areas are chronically affected by artificial flood and inundation problem:

(i) Zoo Narengi road on both sides of Geetanagar hill.

(ii) G.N.B. road from Guwahati Club to Noonmati.

(iii) R.G. Barua road covering Nabin Nagar, Anil Nagar and Ambikagiri Nagar.

(iv) Rajgarh road covering Pub Sarania, Lachit Nagar and part of Nabin Nagar.

(v) G.S. road covering area of Ananda Nagar, Dwarka Nagar, MLA Hostel Complex, Mathura Nagar, Rukmini Nagar and Tarun Nagar.

(vi) VIP Road covering area vicinity of Shankar Dev Kalakhetra, Juri Par and Chachal area.

(vii) Shantipur, Bharalumukh area.

(viii) B. Barua road, Hedayatpur, Gandhi basti area.

(ix) Garigaon area in the west of Jalukbari.

Figure 3 shows the ill effects of flood in the Guwahati City [4] during the year 2014.

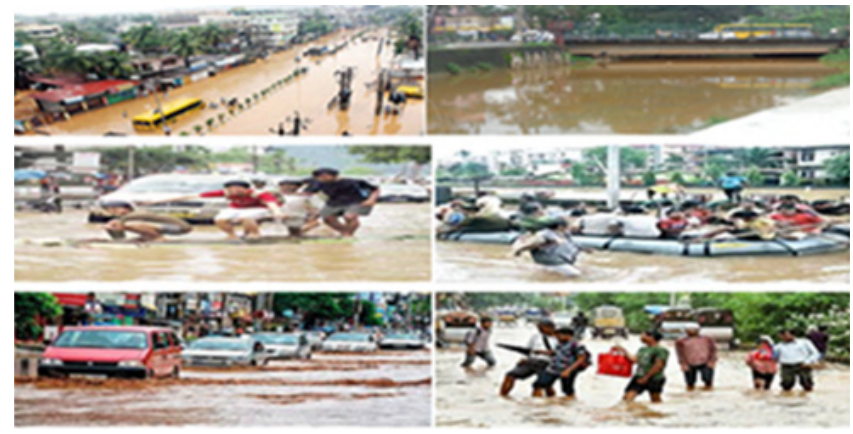

Figure 3: Floods in Guwahati City during the year 2014.

\subsection{Possible measures for mitigation of this hazard}

\subsubsection{Long term measures}

(a) A comprehensive study based on GIS techniques need to be taken to identify the flood prone areas of the city and differentiate the areas according to the vulnerabilities and prepare a detailed flood zone map.

(b) Study and review the detailed mapping of the flood zone and drainage system and prepare a DEM of the order of $0.5 \mathrm{~m}$.

(c) Development of a hydraulic model [8] for the drainage system/covering both underground sewers and surface drains.

(d) Study of the drainage management measures including pumping, construction of sluice gates, retention basins, expansion and dredging of the existing drains etc.

(e) A multidisciplinary water shed approach with special emphasis on the soil conservation in the surrounding hills of the city need to be carried out. 


\subsubsection{Short term measures}

(a) Natural diversion of surface water coming down from the hills on the south eastern part of the city to the Brahmaputra River through Silsako Beel.

(b) Similar diversion of Bahini River from the G.S. road crossing point towards Silsako Beel to be finally discharged to Brahmaputra River.

(c) Diversion of Basistha and Mora Bharalu River towards the Kushi River instead of allowing these two rivers to discharge at Deepor Beel.

(d) Increase the capacity of the pump installed at various locations of the city and immediate repairing of the sluice gates wherever installed to prevent bad flow of water.

(e) Regular cleaning of the drains and rivers from debris and muds to allow free flow of water as per natural slope of the city.

(f) Removal of all encroachment alongside the natural drainage and the water bodies so that their capacity to retain water increases.

(g) Construction of some silt traps to resist the flow of silt and mud from the hills resulting in choaking of road side drains that prevents the flow of water to the ultimate discharge point.

\subsection{Strategies for remedial actions [6]}

There is no necessity to repeat that urban flood creates considerable infrastructure problems and huge economic losses, as well as significant damage to property and goods. Therefore the basic policy for a comprehensive effort to deal with the problem of floods in this city is to go for a natural resources planning, development and manage by adopting integrated approach for a hydrological unit such as a watershed concept, incorporating quantity, quality and environmental considerations. A few remedial actions related to the above mentioned strategy are given below:

(a) Prevention of alteration of topography in the catchment, up-gradation of drains from top of the catchment to its outlet for handling increase in run off.

(b) Adoption of catchment management practices and enforcing its compliance.

(c) Preparation of a flood level plan to a datum for using them to control building floors and other development.

(d) Reconstruction to a standard equal to the future drain requirements.

(e) Man hole levels need to be lowered and reconstruction of sewer below the drain invert.

(f) Implementation of solid waste plan.

(g) Identification of soil erosion site and development of proper silt control structure.

(h) The Metropolitan Development Authority of the city need to undertake the risk assessment activity and facilitate developing a robust response plan including rapid restoration of basic services [9].

\subsection{Efforts made to mitigate the floods [5]}

The Guwahati Metropolitan Development Authority with the help of the Water Resources Department, Government of Assam and Guwahati Municipal 
Corporation had undertaken a few positive steps [10] during the year 2015 to mitigate the flood hazard in the city as mentioned below:

(a) In addition to the 6 existing pumps having total capacity of 7,000 litres/sec at the outlet of Bharalu River in Bharalumukh, 4 more pumps each having capacity of 1,667 litres/sec have been installed raising the discharge capacity to 13,668 litres/sec to pump out the flood water to the Brahmaputra River.

(b) Four numbers of new pumps each having capacity of 1,000 litres/sec are installed at Mora Bharalu outfall with Pamohi with a sluice gate with shutter having capacity of 30 cumec is newly constructed.

(c) Two new pumps having capacity of 1,700 litres/sec each have been installed at the Lakhimijan outfall with Basistha River and a newly constructed sluice gate with 30 cumec capacity is provided.

(d) At Bondajan outfall with Brahmaputra one more sluice gate is constructed having capacity of 30 cumec and 2 new pumps of 1700 litres/sec each are installed.

(e) Dredging and resectioning of the Bharalu River from the GaneshguriHengerabari road crossing point to Bharalumukh and Basistha River from $\mathrm{NH}$ crossing up to Depar Beel was done (Figure 4(a) and (b)) [10].

(f) Some improvement of the drain from Veterinary College campus at Khanapara up to Juri par have been made.

(g) A new RCC culvert across the NH-37 near the ISBT has been constructed to drain out the water from Basistha River to Deepor Beel.

(h) In addition to the installation of additional pumps mentioned above numerous smaller capacity pumps are placed at about ten different locations in the waterlogged areas of the city for draining out the water as quickly as possible.

(i) New pumps are installed at Bhangagarh point in Bharalu River to pump out water from the Nabin Nagar and Tarun Nagar waterlogged area (Figure 5).

(j) Dredging of the bed in the Mora Bharalu River for a length of $6.5 \mathrm{~km}$ up to the NH-37 crossing was done.

(k) Dredging and bank clearance was done in Bondajan drain up to the Brahmaputra River near Panikhaiti.

(1) Earthen drain alongside the G.S. road from Jorabat to Burnihat was widened.

(m) Earthen drain alongside the NH-37 from Basitha Chariali to ISBT was widened and debris cleared.

(n) Over and above all the structural measures taken by the concerned departments, the District Administration is taking help of the District Disaster Management Authority to use State Disaster Response Force [11] for evacuation of affected citizens and give them proper shelter and food till they return to their houses.

Although the efforts taken so far are of a combination of both short and long term measures, this will bring a temporary relief only. In order to achieve a complete remedial of the problem the authorities responsible need to be more proactive and serious in dealing with this age old $\&$ almost a chronic problem to the citizens of Guwahati. 


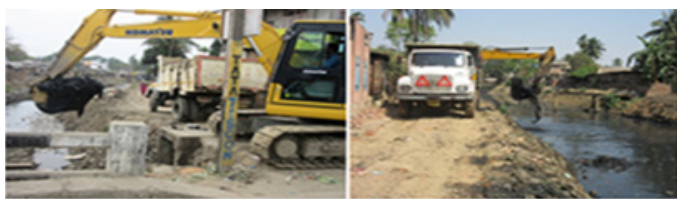

(a)

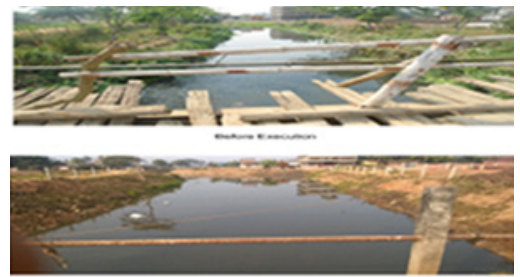

(b)

Figure 4: (a) Desiltation of the Mora Bharalu River in progress. (b) Before and after the re-sectioning of the Basistha.
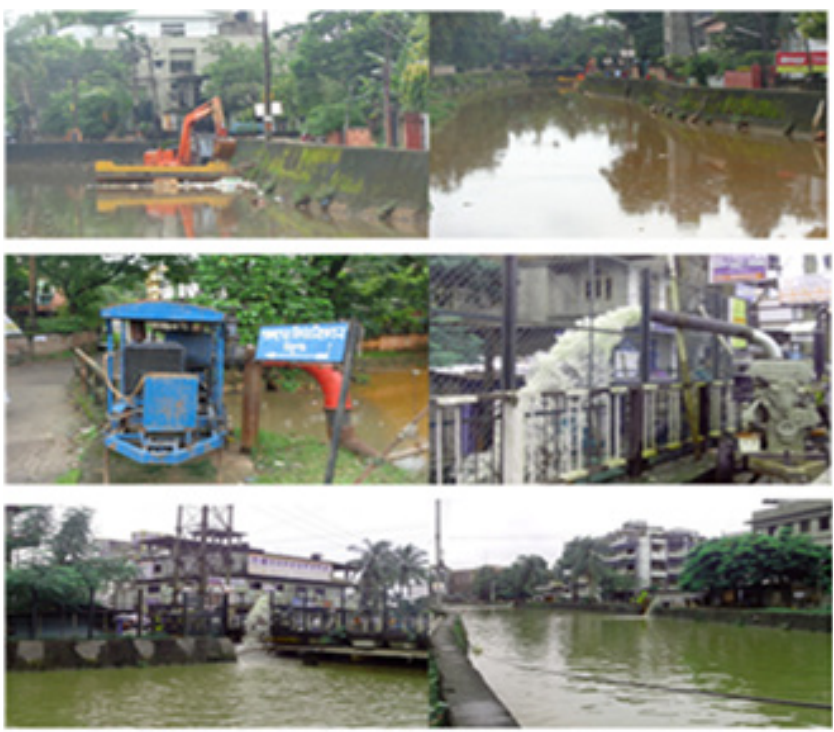

Figure 5: Dredging of river and pumping from the waterlogged areas.

\section{Conclusions}

Sustainable urban development is possible only when there is effective good governance at local levels. There is a need to integrate the functioning of all nodal agencies. It is agreed by all that urban drainage has a direct impact on the city's image, citizen's life and health. If the system does not work properly, it leads to environmental hazards. Improving the drainage system in a city requires not only 
capital infusion but also recurring expenditures, for operation and maintenance. Citizen awareness is another important issue, particularly in respect of ensuring that drainage is not obstructed by illegal construction and dumping of debris in the drain does not occur. Government needs to strictly enforce use of only biodegradable materials for packaging of essential commodities for the citizens.

\section{References}

[1] Management of Urban Flooding by NDMA Guidelines, Government of India, pp. 1-123, September 2010.

[2] City Profile: Guwahati by Renu Desai, Darshini Mahdevia and Aseem Misra, A Centre for Urban Equity Paper, CEPT University, pp. 4-16, August 2014.

[3] National Institute of Disaster Management (NIDM), Government of India Proceedings on Urban Flooding and Management, pp.1-16.

[4] City Development Plan, July, 2006 prepared by the Government of Assam under the JNNURM, pp. 8-15, pp. 43-80, July 2006.

[5] Guwahati Wikipedia, the Free Encyclopedia of Wikimedia Foundation Inc.

[6] Urban Floods; A case study of Bangalore City by T. V. Ramachandra and Pradeep P. Mazumder, April 2009.

[7] Flood Zone Mapping of Guwahati Municipal Corporation Area using GIS by Plabita Barman and Dulal C. Goswami, pp. 1-9, 2009.

[8] Urban Drainage Modeling for Guwahati Metropolitan Area, a project proposal submitted by DHI(I) in October 2015 to AUIIP (Assam Urban Infrastructure Investment Programme) of Asian Development Bank.

[9] Assam Disaster Management Plan prepared by Assam State Disaster Management Authority (ASDMA), Government of Assam, pp. 21-41, 2011.

[10] Power Point Presentation of Water Resource Department (WRD) Assam on Guwahati Drainage in 2015.

[11] Assam Disaster Management Manual, 2015 prepared by Revenue and Disaster Management Department, Government of Assam, pp. 45-78, 2015. 